ERRATUM

Yurii V. Chinenov

\title{
Cytochrome $c$ oxidase assembly factors with a thioredoxin fold are conserved among prokaryotes and eukaryotes
}

Published online: 20 June 2000

(C) Springer-Verlag 2000

\section{J Mol Med (2000) DOI 10.1007/s001090000110}

The figure reprinted on the next page should have been printed in color instead of black and white (Fig. 1).
The online version of the original article can be found at http://dx.doi.org/10.1007/s001090000110

Y.V. Chinenov (®)

Howard Hughes Medical Institute,

University of Michigan Medical Center, 4570 MSRB II,

1150 W. Medical Center Drive, Ann Arbor,

MI 48109-0650, USA

e-mail: yurii@umich.edu

Tel.: +1-734-6152576, Fax: +1-734-6153397

\section{References}

14. Corpet F (1988) Multiple sequence alignment with hierarchical clustering. Nucleic Acids Res 16:10881-10890

16. Jones DT (1999) Protein secondary structure prediction based on position-specific scoring matrices. J Mol Biol 292:195-202

17. Choi HJ, Kang SW, Yang CH, Rhee SG, Ryu SE (1998) Crystallization and preliminary X-ray studies of hORF6, a novel human antioxidant enzyme. Acta Crystallogr D Biol Crystal$\operatorname{logr} 54: 436-437$

18. Hirotsu S, Abe Y, Okada K, Nagahara N, Hori H, Nishino T, Hakoshima T (1999) Crystal structure of a multifunctional 2Cys peroxiredoxin heme-binding protein $23 \mathrm{kDa}$ /proliferationassociated gene product. Proc Natl Acad Sci USA 96:1233312338

23. Papadopoulou LC, Sue CM, Davidson MM, Tanji K, Nishino I, Sadlock JE, Krishna S, Walker W, Selby J, Glerum DM, Coster RV, Lyon G, Scalais E, Lebel R, Kaplan P, Shanske S, De Vivo DC, Bonilla E, Hirano M, DiMauro S, Schon EA (1999) Fatal infantile cardioencephalomyopathy with COX deficiency and mutations in SCO2, a COX assembly gene. Nat Genet 23:333-337

31. Nicholas KB, Nicholas HB Jr, Deerfield DWI (1997) GeneDoc: Analysis and Visualisation of Genetic Variation. http://www.cris.com/ Ketchup/genedoc.shtml 


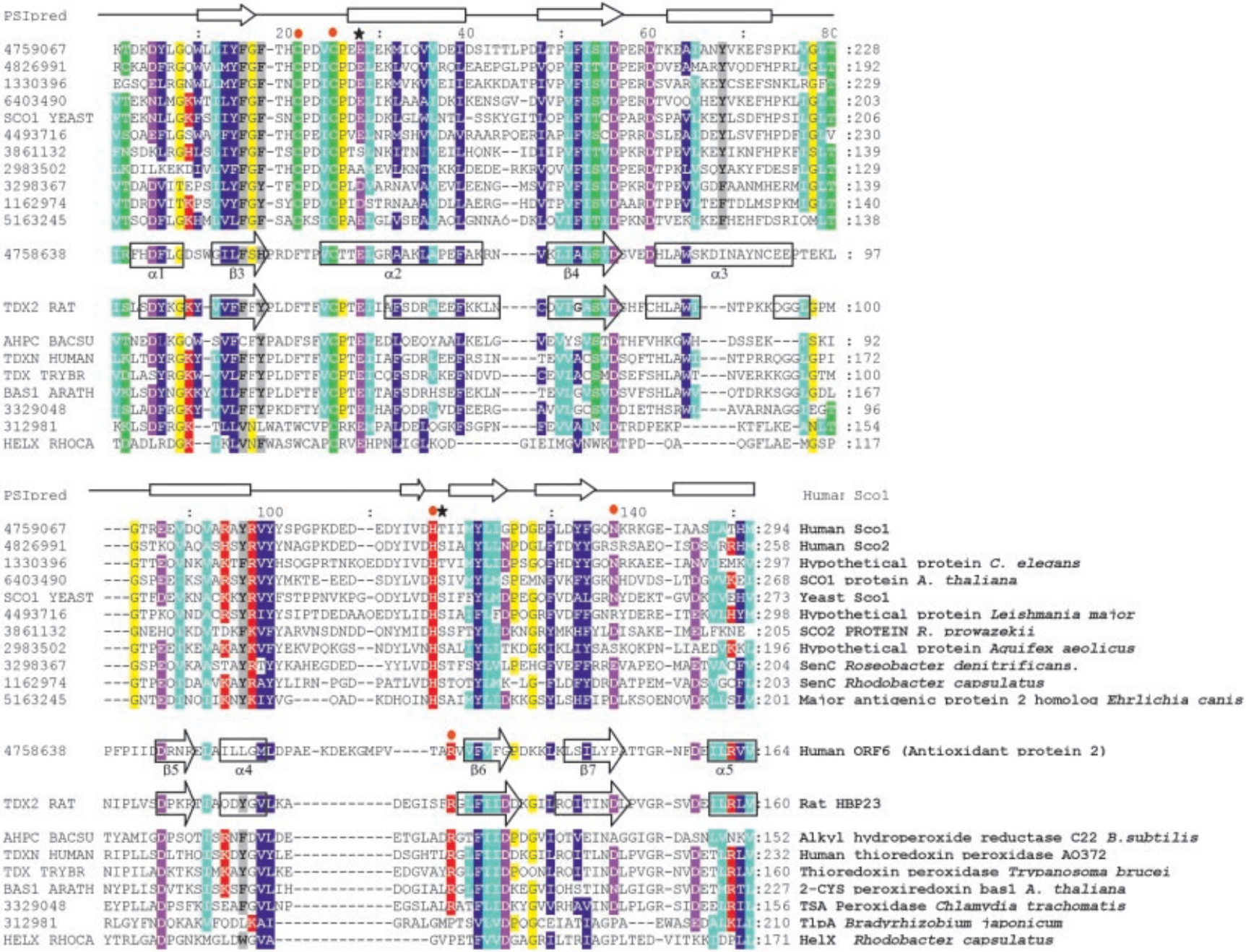

Fig. 1 Multiple alignment of Sco1-related proteins. A PSI BLAST search $(\mathrm{E}$-value $=0.001)$ of NCBI nonredundant protein database with the C-terminal portion of Saccharomyces cerevisae Scolp revealed similarity to peroxiredoxins after the second iteration and bacterial thiol:disulfide oxidoreductases after the third iteration. Representative members of these groups were aligned using MULTALIN [14] with the following settings: symbol comparison table - BLOSUM 62, gap penalty 8, gap penalty at extension 0.05 . Aligned sequences were prepared for publication using GenDoc [31]. Conserved amino acids were colored according to the following scheme: dark blue hydrophobic residues (ACFGHIKLMVWY); light blue aliphatic residues (ILV); gray aromatic residues (FHWY); red positively charged residues (KRH); purple DENQ; green polar (CDEHKNQRST); yellow small (ACDGNPSTV). Left column SwissProt protein names or GenBank identifier codes; right column amino acid positions are indicated for each protein; on the top of the alignment amino acid positions of aligned proteins; above the alignment with open rectangles secondary structure predicted with PSIpred [16], $\alpha$-helixes; open arrows $\beta$ strands. Secondary structure of human AOP2 (ORF6) and rat HBP23 is assigned from respective crystal structures and is shown as following: black rectangles $\alpha$-helices; black arrows $\beta$-strands. The annotation of secondary structure elements is as in crystal structure of ORF6 [17, 18]. Orange circles residues of the putative active center and Arg-119 of the ORF6 active center; black stars above the alignment amino acid residues in the proposed Sco active center that are mutated in patients with infantile cardioencephalomyopathy [23] 